Open Access

\title{
Bias flow rate and ventilation efficiency during adult high-frequency oscillatory ventilation: a lung model study
}

\author{
Osamu Nagano ${ }^{1 *} \mathbb{D}$, Tetsuya Yumoto ${ }^{2}$, Atsunori Nishimatsu ${ }^{3}$, Shunsuke Kanazawa ${ }^{3}$, Takahisa Fujita ${ }^{3}$, \\ Sunao Asaba $^{3}$ and Hideo Yamanouchi ${ }^{1}$
}

* Correspondence: s99nagano@ kochi-u.ac.jp; onagano2004@yahoo. co.jp

${ }^{1}$ Department of Disaster and Emergency Medicine, Kochi University Medical School, 185-1, Kohasu, Oko-cho, Nankoku, Kochi 783-8505, Japan

Full list of author information is available at the end of the article

\begin{abstract}
Background: Bias flow (BF) is essential to maintain mean airway pressure (MAP) and to washout carbon dioxide $\left(\mathrm{CO}_{2}\right)$ from the oscillator circuit during high-frequency oscillatory ventilation (HFOV). If the $\mathrm{BF}$ rate is inadequate, substantial $\mathrm{CO}_{2}$ rebreathing could occur and ventilation efficiency could worsen. With lower ventilation efficiency, the required stroke volume (SV) would increase in order to obtain the same alveolar ventilation with constant frequency. The aim of this study was to assess the effect of $\mathrm{BF}$ rate on ventilation efficiency during adult HFOV.
\end{abstract}

Methods: The R100 oscillator (Metran, Japan) was connected to an original lung model internally equipped with a simulated bronchial tree. The actual SV was measured with a flow sensor placed at the Y-piece. Carbon dioxide $\left(\mathrm{CO}_{2}\right)$ was continuously insufflated into the lung model $\left(\dot{\mathrm{V}} \mathrm{CO}_{2}\right)$, and the partial pressure of $\mathrm{CO}_{2}\left(\mathrm{PCO}_{2}\right)$ in the lung model was monitored. Alveolar ventilation ( $\dot{V} \mathrm{~A})$ was estimated as $\dot{\mathrm{V}} \mathrm{CO}_{2}$ divided by the stabilized value of $\mathrm{PCO}_{2}$. $\dot{V} A$ was evaluated by setting $\mathrm{SV}$ from 80 to $180 \mathrm{~mL}(10 \mathrm{~mL}$ increments, $n=5$ ) at a frequency of $8 \mathrm{~Hz}$, a MAP of $25 \mathrm{cmH}_{2} \mathrm{O}$, and a BF of 10, 20, 30 , and $40 \mathrm{~L} / \mathrm{min}$ (study 1). Ventilation efficiency was calculated as $\dot{V} A$ divided by the actual minute volume. The experiment was also performed with an actual SV of 80,100 , and $120 \mathrm{~mL}$ and a BF from 10 to $60 \mathrm{~L} / \mathrm{min}$ (10 L/min increments: study 2).

Results: Study 1: With the same setting SV, the $\dot{V} A$ with a BF of $20 \mathrm{~L} / \mathrm{min}$ or more was significantly higher than that with a BF of $10 \mathrm{~L} / \mathrm{min}$. Study 2: With the same actual SV, the $\dot{V} A$ and the ventilation efficiency with a BF of $30 \mathrm{~L} /$ min or more were significantly higher than those with a BF of 10 or $20 \mathrm{~L} / \mathrm{min}$.

Conclusions: Increasing BF up to $30 \mathrm{~L} /$ min or more improved ventilation efficiency in the R100 oscillator.

Keywords: High-frequency oscillatory ventilation (HFOV), Bias flow rate, Ventilation efficiency, Actual stroke volume

\section{Background}

Bias flow (BF) is essential to maintain mean airway pressure (MAP) and to washout carbon dioxide $\left(\mathrm{CO}_{2}\right)$ from the oscillator circuit (" $\mathrm{CO}_{2}$ washout") during high-frequency oscillatory ventilation (HFOV). If the $\mathrm{BF}$ rate is inadequate, substantial $\mathrm{CO}_{2}$ rebreathing could occur, and the resultant hypercapnia might become a problem [1, 2]. This situation increases wasted ventilation and worsens ventilation efficiency. With lower ventilation

(c) The Author(s). 2018 Open Access This article is distributed under the terms of the Creative Commons Attribution 4.0 International License (http://creativecommons.org/licenses/by/4.0/), which permits unrestricted use, distribution, and reproduction in any medium, provided you give appropriate credit to the original author(s) and the source, provide a link to the Creative Commons license, and indicate if changes were made. 
efficiency, the required stroke volume (SV) must increase in order to obtain the same alveolar ventilation with constant frequency.

The SensorMedics 3100B oscillator (CareFusion, Yorba Linda, CA, USA) has often been used with a $\mathrm{BF}$ of 30 or $40 \mathrm{~L} / \mathrm{min}$ [3-5]. For the R100 oscillator (Metran Co. Ltd., Kawaguchi, Saitama, Japan), a BF of 20 to $40 \mathrm{~L} / \mathrm{min}$ is recommended in Japan, although a $\mathrm{BF}$ of $30 \mathrm{~L} / \mathrm{min}$ or more has been preferred in many institutions, especially in patients with spontaneous breathing. Some studies have investigated the effect of the BF rate $[1,2,6,7]$, although none have reported the exact effect of the BF rate on ventilation efficiency during adult HFOV. The aim of this study is to assess the effect of the BF rate on ventilation efficiency using the R100 oscillator.

\section{Methods}

\section{Experimental setting}

The R100 oscillator was connected to the lung model via an angle-type connector and an endotracheal tube (ETT) with an internal diameter of $8.0 \mathrm{~mm}$ and a length of $30 \mathrm{~cm}$ (Fig. 1). A microelectromechanical systems mass flow sensor (Siargo FS6022B150, Siargo Ltd., Santa Clara, CA, USA) was placed between the angle-type connector and the Y-piece for the actual SV (aSV) measurement. The total dead space volume (VD) was approximately $110 \mathrm{~mL}$, and the airway resistance was approximately $2.0 \mathrm{cmH}_{2} \mathrm{O} / \mathrm{L} /$ s. The common oscillator settings during the experiments were as follows: frequency of $8 \mathrm{~Hz}, \mathrm{MAP}$ of $25 \mathrm{cmH}_{2} \mathrm{O}$, and fraction of inspired oxygen of 0.21 . The inspiratory time was fixed at $50 \%$ in this oscillator. The heated humidifier was turned off.

\section{Measurement of actual stroke volume (aSV)}

The aSV was measured with a prototype SV measurement system (Metran Co. Ltd., Kawaguchi, Saitama, Japan). In this system, the analogue flow signal was sampled at $200 \mathrm{~Hz}$ and digitally integrated to determine expiratory SV every second using a computer data acquisition system (LabView Ver. 14, National Instruments, Austin, TX, USA). The mean value of 60 data measurements for 1 min was calculated as the aSV.

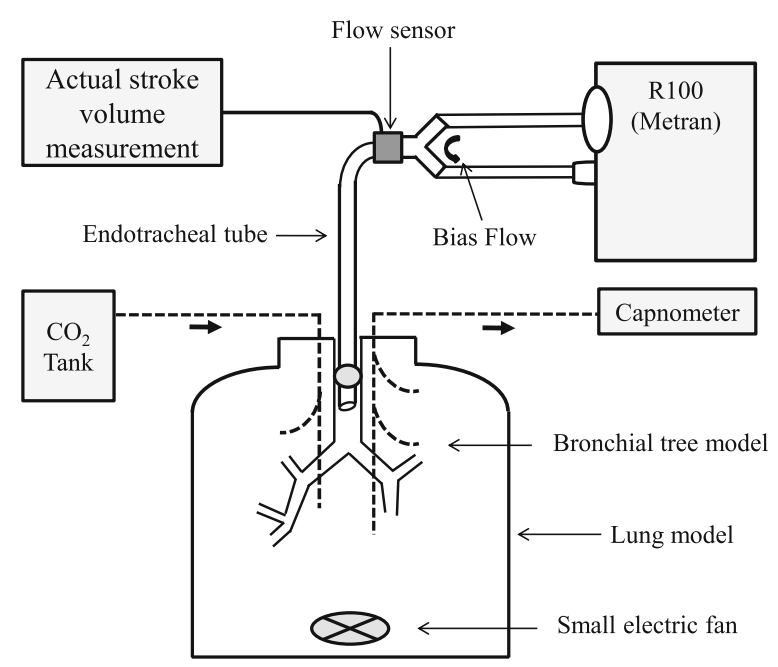

Fig. 1 Schema of the experimental setting. Legend: For more information, see the text 


\section{Lung model}

The lung model consisted of a 20-L airtight rigid plastic container internally equipped with a simulated bronchial tree (KYOTO KAGAKU Co. Ltd., Kyoto, Japan) that had three to seven steps of bifurcations to 20 segmental bronchial branches (Fig. 1). The top of the ETT was located $3.5 \mathrm{~cm}$ from the carina. The total $20 \mathrm{~L}$ volume of the container accounts for an adiabatic static compliance of $19.3 \mathrm{~mL} / \mathrm{cmH}_{2} \mathrm{O}$ (approximately equal to severe ARDS [8]) due to gas compression. The container had two ports for gas insufflation and for gas sampling. A small electrical fan was placed horizontally on the bottom to assist gas mixing in the container.

\section{Measurement of alveolar ventilation (V́a)}

$\mathrm{CO}_{2}$ was insufflated into the lung model at approximately $200 \mathrm{~mL} / \mathrm{min}$ (float-type area flowmeter), and continuous gas sampling was performed from the lung model using a capnometer (Life Scope TR, NIHON KOHDEN Co., Tokyo, Japan) (Fig. 1). The gas sampling rate of the capnometer was set at $200 \mathrm{~mL} / \mathrm{min}$. The partial pressure of $\mathrm{CO}_{2}$ $\left(\mathrm{PCO}_{2} ; \mathrm{mmHg}\right)$ was monitored by the capnometer, and the stabilized value was recorded. The actual minute volume of insufflated $\mathrm{CO}_{2}\left(\dot{\mathrm{V}} \mathrm{CO}_{2} ; \mathrm{mL} / \mathrm{min}\right)$ was calculated by the measurement of $\mathrm{PCO}_{2}$ using the capnometer when it was mixed with oxygen at $5 \mathrm{~L} / \mathrm{min}$ (fixed-type flowmeter). This was performed before starting the experiment and was confirmed every 1 to $2 \mathrm{~h}$. The $\dot{\mathrm{V}} \mathrm{A}$ was estimated by applying the alveolar ventilation equation $\left(\mathrm{PCO}_{2}=0.863 \times \dot{\mathrm{V} C O} / \mathrm{VA}, \mathrm{PCO}_{2}\right.$ and $\dot{\mathrm{V} A}$ : BTPS, $\dot{\mathrm{V}} \mathrm{CO}_{2}$ : $\mathrm{STPD})$, though the equation was rearranged and used as $\dot{\mathrm{VA}}=\dot{\mathrm{V}} \mathrm{CO}_{2} / \mathrm{PCO}_{2}$ because all experiments were done under room temperature and dry conditions.

Although the SV can be set at up to $205 \mathrm{~mL}$ with a frequency of $8 \mathrm{~Hz}$ in the R100 oscillator, the measurable range of the flow sensor was limited. Therefore, $\dot{V}$ A was evaluated with the SV setting (sSV) from 80 to $180 \mathrm{~mL}$ (10 mL increments) and with the BF from 10 to $40 \mathrm{~L} / \mathrm{min}(10 \mathrm{~L} / \mathrm{min}$ increments; study 1$)$. Additionally, the ratio of $\dot{\mathrm{VA}}$ to the actual minute ventilation volume $(\mathrm{a} \dot{\mathrm{V}} \mathrm{E} ; \mathrm{aSV} / 1000 \times 8 \times 60, \mathrm{~L} / \mathrm{min})$ was calculated $(\dot{\mathrm{V}} \mathrm{A} / \mathrm{a} \dot{\mathrm{V}} \mathrm{)})$ as an index for ventilation efficiency. $\dot{V}$ A was also evaluated with the targeted aSV of 80 , 100 , and $120 \mathrm{~mL}$ and with the BF of 10 to $60 \mathrm{~L} / \mathrm{min}(10 \mathrm{~L} / \mathrm{min}$ increments; study 2). Because the BF rate can be set from 10 to $40 \mathrm{~L} / \mathrm{min}$ in the $\mathrm{R} 100$ oscillator, air was added to the BF supply port using a float-type area flowmeter. To further examine the role of BF, the relationship between $\dot{V} A$ and a $\dot{V} E / B F$ was investigated in study 2 .

Each experiment was conducted five times.

\section{Statistical analysis}

The statistical analysis was performed with BellCurve for Excel ver. 2.02 (SSRI Co. Ltd., Tokyo, Japan) using one-way analysis of variance followed by Tukey's test. $P<0.05$ was considered statistically significant. Curve fitting was also performed by the same software.

\section{Results}

Study 1

Figure 2 shows the relationships between sSV and aSV at respective BF rates. The aSV was proportional to the $\mathrm{SSV}$ at all BF rates. Increasing the BF rate decreased the aSV at 


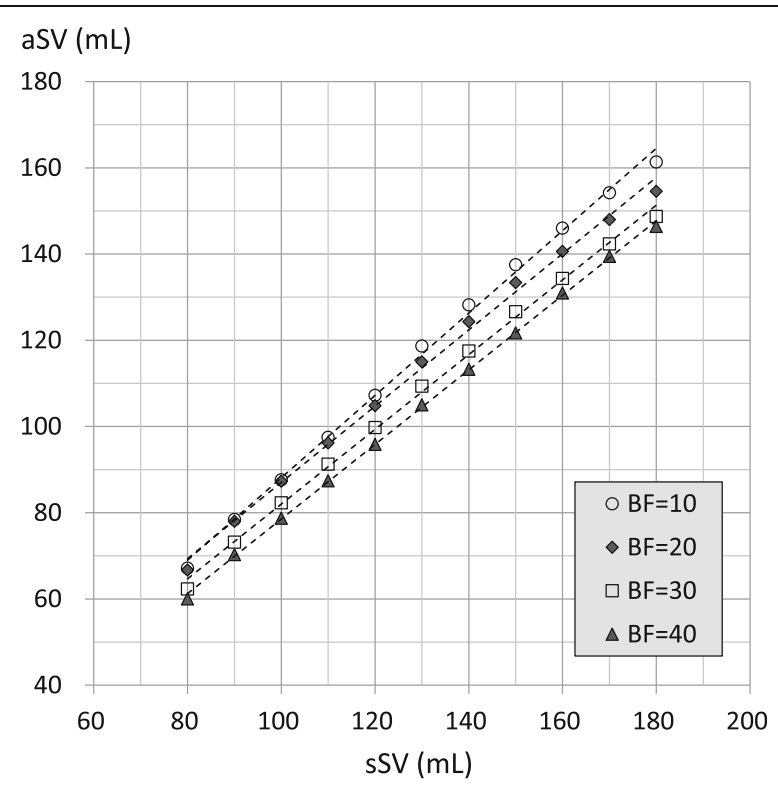

Fig. 2 Relationship between setting stroke volume (sSV) and actual stroke volume (aSV). Legend: Marker indicates the mean value of aSV $(n=5)$. Standard deviation is not indicated. The results of statistical significance test are as follows: $\mathrm{BF}=10$ vs $\mathrm{BF}=20$, ns with $\mathrm{SSV}=80-110, P<0.05$ with $\mathrm{SSV}=120, P<0.01$ with $\mathrm{sSV}=130-150, P<0.001$ with sSV $=160-180 ; \mathrm{BF}=10$ or 20 vs $\mathrm{BF}=30$ or $40, P<0.001$ with all $\mathrm{sSV}$; and $\mathrm{BF}=30$ vs $\mathrm{BF}=40, P<0.05$ with sSV $=80$ and 160-170, $P<0.01$ with SSV $=90$ and 130-150, $P<0.001$ with $s S V=100-120$, ns with sSV $=180$. Dotted lines are the first-order approximations. The coefficient of correlations $(R)$ and $P$ values are as follows: $B F=10$ : $R=0.998, P<0.001 ; \mathrm{BF}=20: R=0.998, P<0.001 ; \mathrm{BF}=30: R=0.998, P<0.001 ;$ and $\mathrm{BF}=40: R=0.999, P<0.001$

most settings. In all sSVs, the aSV with a BF of 30 or $40 \mathrm{~L} / \mathrm{min}$ was significantly lower than that with a BF of 10 or $20 \mathrm{~L} / \mathrm{min}(P<0.001)$. The airway pressure amplitude (AMP) measured at the Y-piece (displayed on the panel of the R100 oscillator) showed a similar change (Additional file 1). Figure 3 shows the relationships between sSV and $\dot{\mathrm{V} A}$ at respective BF rates. The $\dot{\mathrm{VA}}$ was correlated to the power of SSV at all BF rates. The perfect powers were 1.226, 1.580, 1.744, and 1.819 with BFs of 10, 20, 30, and $40 \mathrm{~L} / \mathrm{min}$, respectively. In all sSVs, the $\mathrm{VA}$ with a BF of $20 \mathrm{~L} / \mathrm{min}$ or more was significantly higher than the $\dot{V}$ A with a $B F$ of $10 \mathrm{~L} / \mathrm{min}$ (the $P$ value was different for the sSV). The $\dot{\mathrm{V} A}$ with a $\mathrm{BF}$ of 30 or $40 \mathrm{~L} / \mathrm{min}$ was not significantly higher than the $\dot{\mathrm{V}} \mathrm{A}$ with a BF of $20 \mathrm{~L} / \mathrm{min}$ in all sSVs. The $\dot{\mathrm{V} A}$ with BFs of 30 and $40 \mathrm{~L} / \mathrm{min}$ was not significantly different in all sSVs.

Figure 4 shows the relationships between aSV and $\dot{V A}$ at respective BF rates (individual data). The $\dot{V} A$ was correlated with the power of the aSV at all BF rates. The perfect power were 1.128, 1.528, 1.631, and 1.664 with BFs of 10, 20, 30, and $40 \mathrm{~L} / \mathrm{min}$, respectively. It appeared that the $\dot{\mathrm{V}} \mathrm{A}$ increased with an increasing $\mathrm{BF}$ up to $30 \mathrm{~L} / \mathrm{min}$ with an aSV of more than approximately $100 \mathrm{~mL}$ (a statistical analysis was not conducted).

Figure 5 shows the relationships between aSV and $\dot{\mathrm{V}} \mathrm{A} / \mathrm{a} \dot{\mathrm{V}} \mathrm{E}$ at respective $\mathrm{BF}$ rates (individual data). The $\dot{\mathrm{VA}} / \mathrm{a} \dot{\mathrm{V} E}$ was proportional to the aSV at all BF rates. It appeared that the $\dot{V} A / a \dot{V} E$ increased with an increasing BF up to $30 \mathrm{~L} / \mathrm{min}$ with an aSV of more than approximately $100 \mathrm{~mL}$ (a statistical analysis was not conducted). 


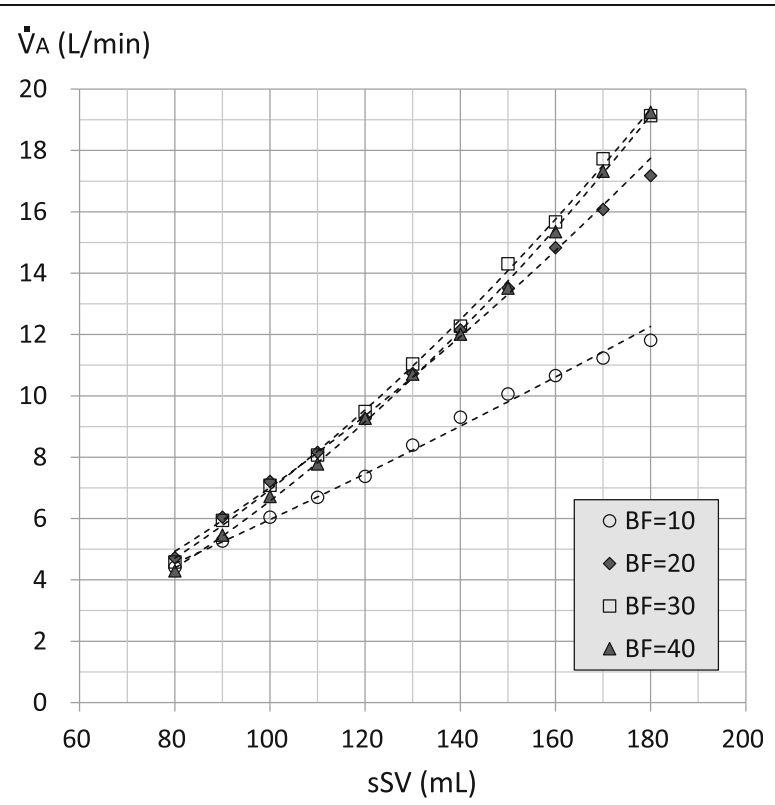

Fig. 3 Relationship between setting stroke volume (sSV) and alveolar ventilation (VA). Legend: Marker indicates the $S S V$ and mean value of $\dot{V A}(n=5)$. Standard deviation is not indicated. The results of the statistical significance test are as follows: $\mathrm{BF}=10$ vs $\mathrm{BF}=20, P<0.001$ with all $\mathrm{SSV} ; \mathrm{BF}=10$ vs $\mathrm{BF}=30, P<0.01$ with $s S V=80, P<0.001$ with $\mathrm{SV}=90-180 ; \mathrm{BF}=10$ vs $\mathrm{BF}=40, P<0.05$ with $\mathrm{sSV}=80-90, P<0.001$ with $\mathrm{sSV}=100-180 ; \mathrm{BF}=20 \mathrm{vs} \mathrm{BF}=30$, $P<0.05$ with $\mathrm{sSV}=80,130$, and 150 , ns with $\mathrm{SSV}=90-120$ and $140, P<0.01$ with $\mathrm{sSV}=160, P<0.001$ with $\mathrm{sSV}=170-180 ; \mathrm{BF}=20$ vs $\mathrm{BF}=40, P<0.001$ with $\mathrm{sSV}=80-100$ and $170-180, P<0.01$ with $\mathrm{sSV}=110$, ns with $s S V=120-160$; and $B F=30$ vs $B F=40, P<0.001$ with $s S V=80-100, P<0.05$, with $s S V=110,130$, and 150 , ns with $\mathrm{SSV}=120,140$, and 160-180. Dotted curves are power approximations. The perfect powers (coefficient of correlation: $R, P$ value) are as follows: $\mathrm{BF}=10: 1.226(R=0.995, P<0.001) ; \mathrm{BF}=20: 1.580$ $(R=0.998, P<0.001) ; \mathrm{BF}=30: 1.744(R=0.995, P<0.001) ;$ and $\mathrm{BF}=40: 1.819(R=0.994, P<0.001)$

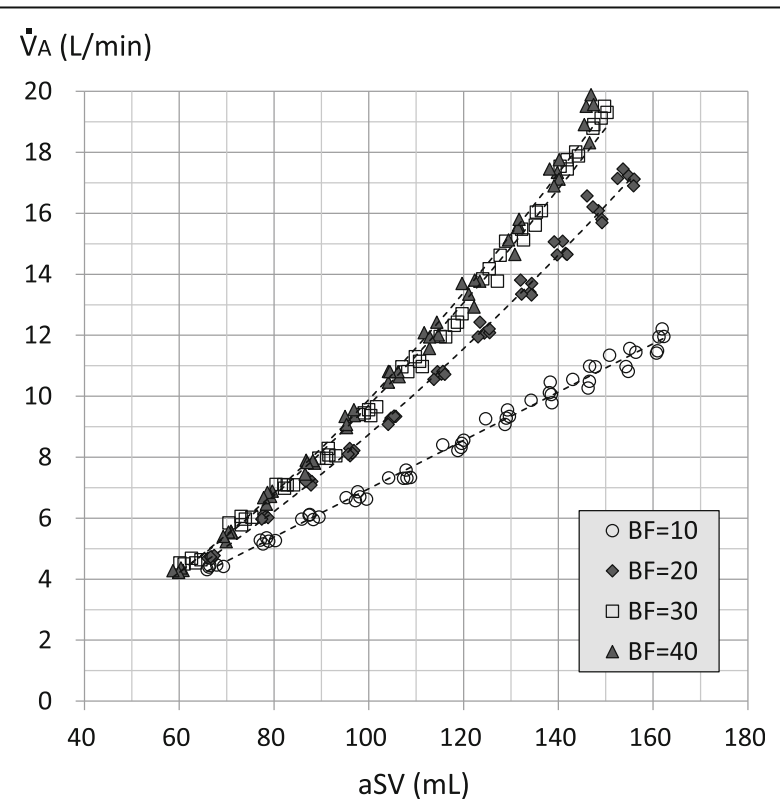

Fig. 4 Relationship between actual stroke volume (aSV) and alveolar ventilation (VA). Legend: Markers indicate individual data of aSV and $\dot{V} A$. Dotted curves are power approximations. The perfect powers (coefficient of correlation: $R, P$ value) are as follows: $\mathrm{BF}=10: 1.128(R=0.996, P<0.001) ; \mathrm{BF}=20: 1.528(R=0.995, P<0.001)$; $\mathrm{BF}=30: 1.631(R=0.992, P<0.001) ;$ and $\mathrm{BF}=40: 1.664(R=0.992, P<0.001)$ 


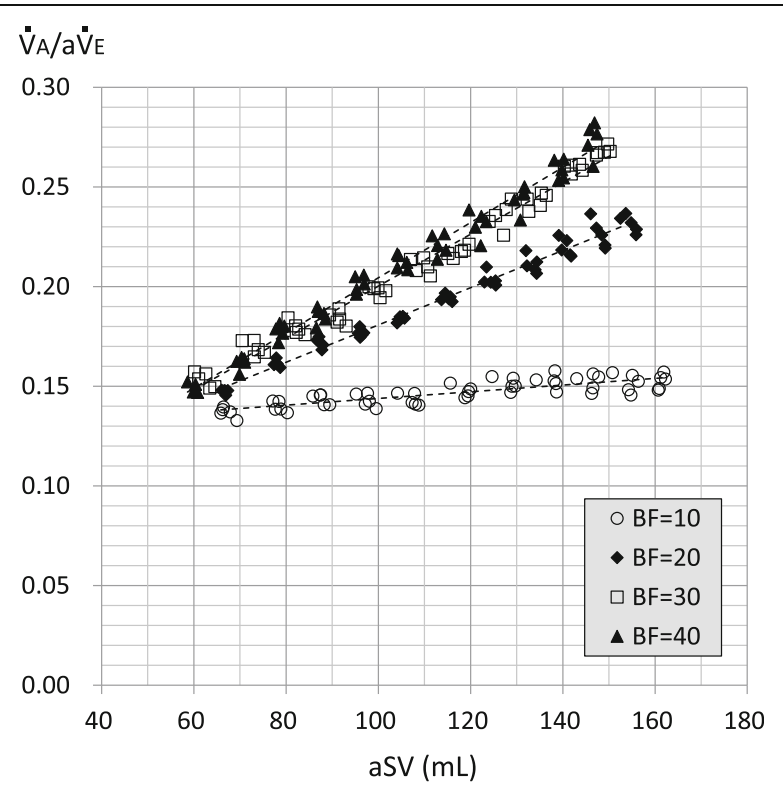

Fig. 5 Relationship between actual stroke volume (aSV) and ventilation efficiency (VंA/aVंE). Legend: Markers indicate individual data of aSV and $\dot{V} A / a \dot{V} E$. Dotted lines are the first-order approximations. The coefficient of correlations $(R)$ and $P$ values are as follows: $\mathrm{BF}=10: R=0.824, P<0.001 ; \mathrm{BF}=20: R=0.989, P<0.001 ; \mathrm{BF}=$ 30: $R=0.990, P<0.001 ;$ and $\mathrm{BF}=40: R=0.996, P<0.001$

\section{Study 2}

aSVs with the target of 80,100 , and $120 \mathrm{~mL}$ were not significantly different at respective BF rates (Additional file 2). Figure 6 shows the $\dot{V} A$, and Fig. 7 shows the $\dot{V} A / a \dot{V E}$ with the targeted aSV of 80, 100, and $120 \mathrm{~mL}$. In all targeted aSVs, the $\dot{\mathrm{V} A}$ and the $\dot{\mathrm{V}}$ $\mathrm{A} / \mathrm{aV} E$ with a $\mathrm{BF}$ of $20 \mathrm{~L} / \mathrm{min}$ or more were significantly higher than those with a BF of $10 \mathrm{~L} / \mathrm{min}(P<0.001)$, and those with a BF of $30 \mathrm{~L} / \mathrm{min}$ or more were significantly higher than those with a BF of $20 \mathrm{~L} / \mathrm{min}(P<0.001)$. In all targeted aSVs, the $\dot{\mathrm{V}} \mathrm{A}$ and the $\dot{\mathrm{VA}} / \mathrm{aVE}$ with a BF of 50 or $60 \mathrm{~L} / \mathrm{min}$ were significantly higher than those with a BF of $30 \mathrm{~L} / \mathrm{min}$ (the $P$ value was different for the targeted aSV with a $\mathrm{BF}$ of $50 \mathrm{~L} / \mathrm{min}$, and $P<0.001$ with a BF of $60 \mathrm{~L} / \mathrm{min})$.

Figure 8 shows the relationships between a $\dot{V} E / B F$ and $\dot{V} A$ with respective targeted aSVs (individual data). The $\dot{\mathrm{V}} \mathrm{A}$ was correlated to the exponential of the a $\dot{\mathrm{V}} \mathrm{E} / \mathrm{BF}$ with all targeted aSVs. The $Y$-intercepts were 7.54 with a targeted aSV of $80 \mathrm{~mL}, 11.46$ with a targeted aSV of $100 \mathrm{~mL}$, and 15.31 with a targeted aSV of $120 \mathrm{~mL}$.

\section{Discussion}

We investigated the effect of the BF rate on alveolar ventilation and ventilation efficiency using an original lung model in the adult oscillator R100, and our study showed that increasing the BF rate improved the ventilation efficiency up to $30 \mathrm{~L} / \mathrm{min}$ or more with a frequency of $8 \mathrm{~Hz}$. This result is almost consistent with the previous large animal study [1], though the used frequency, oscillator, and the structure of the circuit were different from our study. In Japan, the R100 oscillator has been often used with the frequency around $8 \mathrm{~Hz}$ or more. In the OSCAR trial which used the R100 


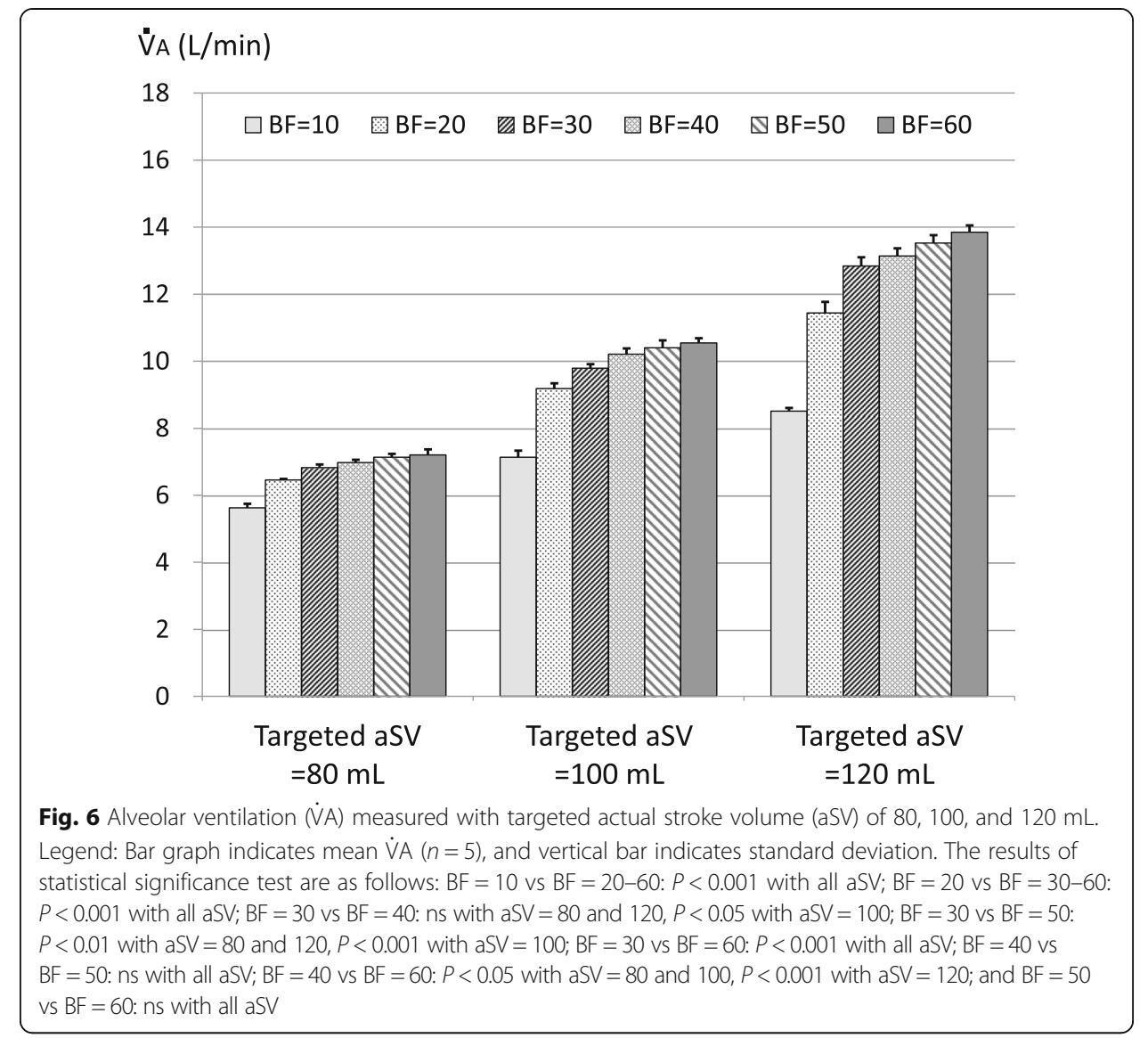

oscillator, the mean frequency was $7.8 \mathrm{~Hz}$ on the first day [9]. We therefore performed the experiments with a frequency of $8 \mathrm{~Hz}$. The initial setting of the BF rate was $20 \mathrm{~L} /$ min, and there was no description of BF change in the management protocol in the OSCAR trial [9]. If the BF rate is inadequate, the resultant higher aSV might tend to impair the benefit of HFOV. In the animal study which showed the superiority of higher frequency for lung protection, the aSV was lower with higher frequency [10]. In their study, it was unclear whether the higher frequency or the lower aSV was more important. However, it might be conceivable that the lower aSV might be beneficial in HFOV as well as in conventional lung protective ventilation [11]. The improvement of ventilation efficiency might be a future direction for reaching the goal of HFOV.

In the previous studies that measured aSV with the $3100 \mathrm{~B}$ oscillator, a pneumotachometer or a hot-wire anemometer was used with a data sampling rate of $1000 \mathrm{~Hz}$ [12, 13]. Iguchi et al. measured aSV with two adult oscillators (3100B and R100) using a position sensor placed on the lung model with a data sampling rate of $667 \mathrm{~Hz}$ [14]. Although the aSV measurements were steady and stable in our study, the data sampling rate of $200 \mathrm{~Hz}$ might not be adequate for the frequency of $8 \mathrm{~Hz}$. Therefore, we averaged the 60 data points for $1 \mathrm{~min}$. However, a higher sampling rate would be desirable for robust reliability of the aSV measurement.

We have used a $20-\mathrm{L}$ plastic container as a lung model $[15,16]$, and we improved it by adding a simulated bronchial tree in this study. An advantage of a lung model study 


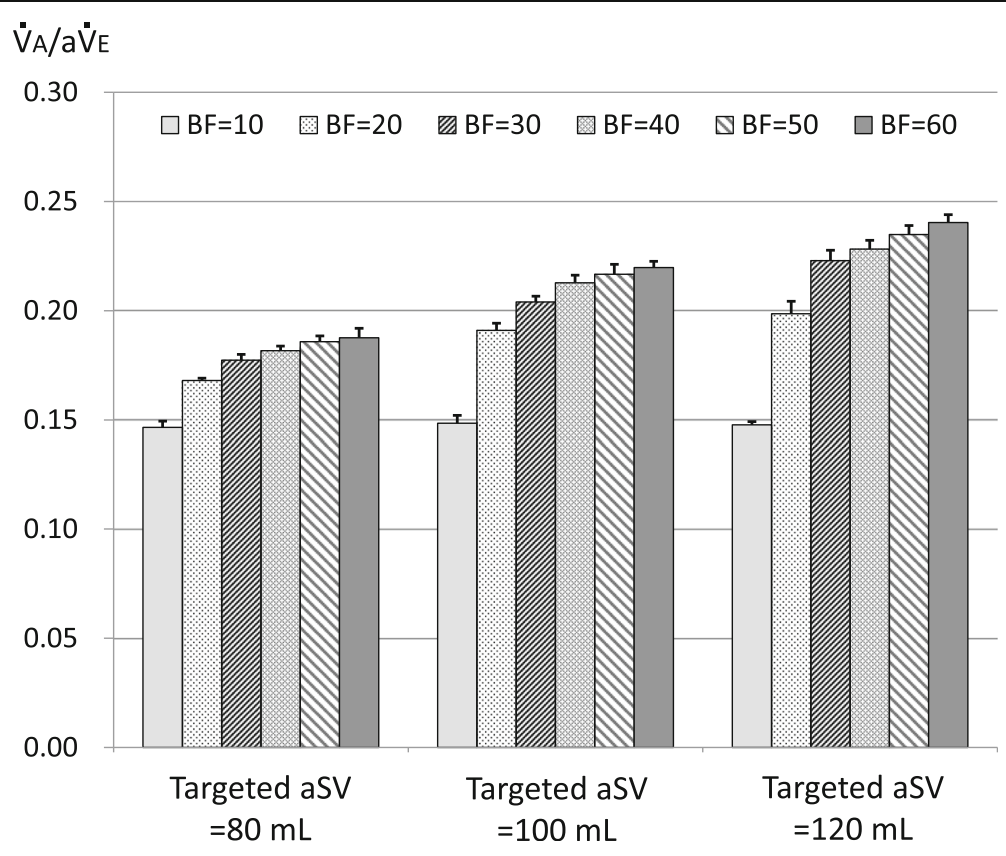

Fig. 7 Ventilation efficiency ( $\dot{V} A$ aViE) measured with targeted actual stroke volume (aSV) of 80, 100, and $120 \mathrm{~mL}$. Legend: Bar graph indicates mean $\dot{V} A a \dot{V} E(n=5)$, and vertical bar indicates standard deviation. The results of statistical significance test are as follows: $B F=10$ vs $B F=20-60: P<0.001$ with all aSV; $B F=20$ vs $B F=30-60$ : $P<0.001$ with all aSV; $\mathrm{BF}=30$ vs $\mathrm{BF}=40$ : $\mathrm{ns}$ with $\mathrm{aSV}=80$ and $120, P<0.01$ with $\mathrm{aSV}=100 ; \mathrm{BF}=30 \mathrm{vs} \mathrm{BF}=50$ : $P<0.001$ with $\mathrm{aSV}=80$ and $100, P<0.01$ with $\mathrm{aSV}=120 ; \mathrm{BF}=30$ vs $\mathrm{BF}=60: P<0.001$ with all aSV; $\mathrm{BF}=40$ vs $\mathrm{BF}=50$ : ns with all aSV; $\mathrm{BF}=40$ vs $\mathrm{BF}=60: P<0.05$ with $\mathrm{aSV}=80$ and $100, P<0.01$ with $\mathrm{aSV}=120$; and $\mathrm{BF}=50$ vs $\mathrm{BF}=60$ : ns with all aSV

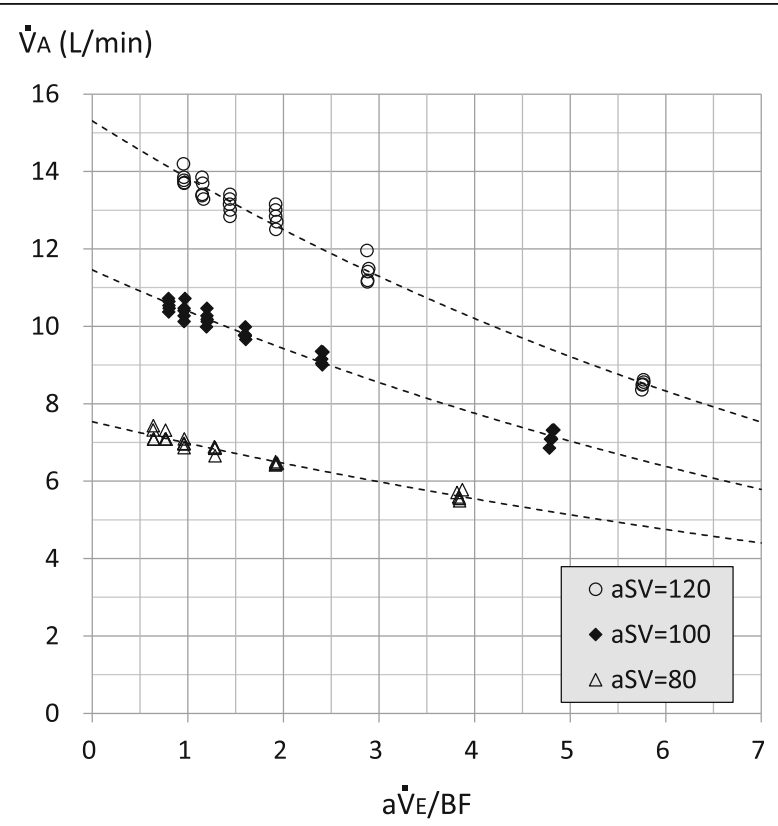

Fig. 8 Relationship between actual minute volume divided by bias flow (aVंE/BF) and alveolar ventilation ( $\dot{\mathrm{V} A})$. Legend: Dotted curves are the exponential approximations. The coefficient of correlations $(R)$ and $P$ values are as follows: aSV = 80: $R=-0.982, P<0.001 ; \mathrm{SV}=100: R=-0.991, P<0.001$; and $\mathrm{aSV}=120: R=-0.992, P<0.001$. The $Y$-intercepts are $7.54(\mathrm{aSV}=80), 11.46(\mathrm{aSV}=100)$, and $15.31(\mathrm{aSV}=120)$ 
is that a wide range of sSVs can be evaluated. However, the simulated bronchial tree in our lung model was quite different from a real lung, with the airway resistance being low and the VD was rather small for an adult. Therefore, the obtained values of $\dot{V} A$ and $\dot{\mathrm{V}} \mathrm{A} / \mathrm{a} \dot{\mathrm{V}} \mathrm{E}$ cannot be applied in clinical situations, and the interpretation of the current results may be difficult. For example, the VंA would be approximately $21 \mathrm{~L} / \mathrm{min}$ with a frequency of $8 \mathrm{~Hz}$, a sSV of $205 \mathrm{~mL}$ (maximum), and a BF of $20 \mathrm{~L} / \mathrm{min}$ in Fig. 3. These settings might be almost equal to the mean setting values of the first day in the OSCAR trial (7.8 Hz and $213 \mathrm{~mL})$ [9]. On the other hand, because the phenomenon that occurs in the lung model must be almost identical with the same aSV and the same frequency, the observed effect of the BF rate in our study must have been caused by different phenomena that occurred in the oscillator circuit. Therefore, it is conceivable that the effect of the BF rate on the ventilation efficiency has a similar tendency in clinical situations.

In clinical or experimental settings, the $\dot{\mathrm{V}} \mathrm{A}$ during HFOV had been determined as frequency $^{a} \times \mathrm{SV}^{b}$ (the values for $a$ and $b$ were approximately 1 and 2, respectively) [17]. Therefore, we applied the power approximation curves to the relationships between sSV or aSV and $\dot{V A}$, and those were well fitted (Figs. 3 and 4). This finding would indicate that our lung model reproduced the particular ventilation mechanism of HFOV to some extent. Although the number of the power was less than two possibly because of the incomplete bronchial tree model, the number of the power was affected by the BF rate (Figs. 3 and 4). We used $\dot{V A} / a \dot{V} E$ as an index of ventilation efficiency in the same way as conventional ventilation, and it was proportional to the aSV (Fig. 5). However, increasing aSV did not increase the ventilation efficiency with the BF of $10 \mathrm{~L} / \mathrm{min}$ (Figs. 5 and 7). Theoretically, the $\dot{\mathrm{VA}} / \mathrm{a} \dot{\mathrm{V} E}$ must be very low, especially in the range of aSV far less than $\mathrm{VD}$, and it must increase with higher aSV, especially in the range of aSV far more than $\mathrm{VD}$, because of the correlation of direct alveolar ventilation (i.e., convection). However, " $\mathrm{CO}_{2}$ washout" from the oscillator circuit would be considerably involved in this issue as discussed in the next paragraph.

In the adult oscillator, the oscillation unit is located on the inspiratory circuit side. Therefore, the major part of the exhaled gas would be pulled out to the inspiratory circuit during the expiratory phase of the oscillation. This has been described as "retrograde $\mathrm{CO}_{2}$ entrainment" in the $3100 \mathrm{~B}$ oscillator [2], and some $\mathrm{CO}_{2}$ rebreathing could naturally occur [1]. Although some gas regurgitation from the expiratory circuit to the inspiratory circuit could occur during the expiratory phase of the oscillation, major gas regurgitation would be prevented by the one-way valve placed at the end of the expiratory circuit in the R100 oscillator. The exhaled gas would mix with the fresh gas in the inspiratory circuit, and the $\mathrm{CO}_{2}$ would be diluted. Then, the mixed gas would go to the lung (aSV) and to the expiratory circuit (BF/cycle) during the next inspiratory phase of the oscillation. The former would include $\mathrm{CO}_{2}$ rebreathing, and the latter would be " $\mathrm{CO}_{2}$ washout." The dilution of exhaled $\mathrm{CO}_{2}$ by the gas mixing in the inspiratory circuit would basically be affected by the ratio of the aSV and the $\mathrm{BF}$ rate per cycle (BF/cycle), that is, the ratio of the $\mathrm{a} \dot{\mathrm{V}} \mathrm{E}$ and the $\mathrm{BF}$ rate per minute. Based on this concept, we examined the relationship between $\dot{\mathrm{V}} \mathrm{A}$ and $\mathrm{a} \dot{\mathrm{V}} \mathrm{E} /$ BF (Fig. 8). Exponential curve fitting was used so that the $X$-intercept would be infinite because the $\dot{V}$ A would be zero without the BF. Although we performed the experiments with a single frequency $(8 \mathrm{~Hz})$, Fig. 8 would suggest that increasing the aSV or 
increasing the frequency would increase the need for a BF rate. The former could be a factor that affected the relationship between the aSV and $\dot{\mathrm{V}} \mathrm{A} / \mathrm{a} \dot{\mathrm{V}} \mathrm{E}$ (Fig. 5), as discussed in the paragraph above. Increasing aSV would promote the ventilation phenomena occurring in the lung model, although the need for BF would increase. Then, increasing aSV would induce a relative insufficiency of BF because of the constant $\mathrm{BF}$ rate in our study. In the case with the $\mathrm{BF}$ of $10 \mathrm{~L} / \mathrm{min}, \mathrm{aVE} / \mathrm{BF}$ is $3.84,4.8$, and 5.76 with the aSV of 80,100 , and $120 \mathrm{~mL}$, respectively. To keep an aVE/BF of 3.84, BF rates of 12.5 and $15 \mathrm{~L} / \mathrm{min}$ are necessary with the aSV of 100 and $120 \mathrm{~mL}$, respectively. This would be a reason why increasing aSV did not increase the ventilation efficiency with the BF of $10 \mathrm{~L} / \mathrm{min}$ (Figs. 5 and 7). All results of our study could be influenced by this issue and must be carefully interpreted. Turner et al. reported that increasing the BF rate had little effect on the ventilation using an infant oscillator (3100A) with BF rates of 10, 20, 30 , and $40 \mathrm{~L} / \mathrm{min}$ [7], although we must consider the fact that they used a juvenile swine (mean body weight $15.1 \mathrm{~kg}$ ) and a relatively low aSV would be used. On the other hand, because it is conceivable that $\mathrm{CO}_{2}$ rebreathing does not occur with an infinite $\mathrm{BF}$ rate, the $Y$-intercepts in Fig. 8 would indicate the upper limits of the improvement of $\dot{\mathrm{V}} \mathrm{A}$ by increasing the $\mathrm{BF}$ rate.

The gas mixing that occurred in the inspiratory circuit could not be completed. Conceptually, the BF might be separated from the gas that completely mixes with the exhaled gas (effective BF) and the gas that does not mix with the exhaled gas (ineffective $\mathrm{BF}$ ). The mean concentration of $\mathrm{CO}_{2}$ exhausted from the expiratory circuit in the steady state must be $\dot{\mathrm{V} C O}{ }_{2} / \mathrm{BF}$. In the case that all BFs are effective BFs, the mean concentration of rebreathing $\mathrm{CO}_{2}$ must be equal to this value. Namely, mean rebreathing $\mathrm{PCO}_{2}$ would be 15.2, 7.6, 5.1, and $3.8 \mathrm{mmHg}$ with BFs of $10,20,30$, and $40 \mathrm{~L} / \mathrm{min}$, respectively, when the $\dot{\mathrm{V} C O}$ is $200 \mathrm{~mL} / \mathrm{min}$. If some BFs are ineffective BFs, rebreathing $\mathrm{PCO}_{2}$ might be higher. Although the ratio of effective $\mathrm{BF}$ is unclear, this concept may help us to understand the mechanism of " $\mathrm{CO}_{2}$ washout" by the BF.

\section{Conclusions}

In this lung model study, ventilation efficiency improved at a BF equal to or more than $30 \mathrm{~L} / \mathrm{min}$ compared to a $\mathrm{BF}$ equal to or less than $20 \mathrm{~L} / \mathrm{min}$ with the R100 oscillator. The mechanism of improving ventilation efficiency by increasing the BF rate would be the decreased $\mathrm{CO}_{2}$ rebreathing, and the need for a $\mathrm{BF}$ rate would depend on a $\dot{\mathrm{V} E}$.

\section{Additional files}

Additional file 1: Relationship between setting stroke volume (sSV) and airway pressure amplitude (AMP) measured at the Y-piece. Legend: Markers indicate the sSV and mean AMP $(n=5)$. Standard deviation is not indicated. The results of the statistical significance test are as follows: $B F=10$ vs $B F=20: P<0.001$ with sSV $=80-110$ and $160-180, P<0.05$ with $\mathrm{SSV}=120$, ns with $\mathrm{sSV}=130-150 ; \mathrm{BF}=10$ or 20 vs $\mathrm{BF}=30$ or $40: P<0.001$ with all $\mathrm{sSV}$; and $\mathrm{BF}=30$ vs $\mathrm{BF}=40$ : ns with $S S V=80, P<0.001$ with SSV $=90-180$. Dotted curves are second-order approximation curves. Coefficient of correlations $(R)$ and $P$ values are as follows: $\mathrm{BF}=10: R=0.992, P<0.001 ; \mathrm{BF}=20: R=0.997, P<0.001 ; \mathrm{BF}=30: R=0.995, P<0.001 ;$ and $\mathrm{BF}=40: R=0.990, P<0.001$. (DOCX $55 \mathrm{~kb})$

Additional file 2: Actual stroke volume (aSV) with targeted aSVs of 80, 100, and $120 \mathrm{~mL}$. Legend: The bar graph indicates the mean aSV $(n=5)$, and the vertical bar indicates the standard deviation. There are no significant differences between BF from 10 to $60 \mathrm{~L} / \mathrm{min}$ with all targeted aSVs. (DOCX $75 \mathrm{~kb}$ ) 
respiratory distress syndrome; aSV: Actual stroke volume; $\mathrm{BF}$ : Bias flow; $\dot{\mathrm{V}} \mathrm{CO}_{2}$ : Minute volume of insufflated $\mathrm{CO}_{2}$; $\mathrm{CO}_{2}$ : Carbon dioxide; ETT: Endotracheal tube; HFOV: High-frequency oscillatory ventilation; MAP: Mean airway pressure; $\mathrm{PCO}_{2}$ : Partial pressure of $\mathrm{CO}_{2} ; \mathrm{RCT}$ : Randomized controlled trial; sSV: Setting stroke volume; SV: Stroke volume; VD: Dead space volume

\section{Acknowledgements}

The authors thank the Metran Co. Ltd. for the use of the prototype SV measurement system.

\section{Availability of data and materials}

The datasets used and/or analyzed during the current study are available from the corresponding author on reasonable request.

\section{Authors' contributions}

The study was designed by ON and TY. ON, TY, AN, SK, TF, and SA collected and analyzed the data. ON and TY prepared the manuscript. HY reviewed the manuscript. All authors read and approved the final manuscript.

\section{Competing interests}

The authors declare that they have no competing interests.

\section{Publisher's Note}

Springer Nature remains neutral with regard to jurisdictional claims in published maps and institutional affiliations.

\section{Author details}

${ }^{1}$ Department of Disaster and Emergency Medicine, Kochi University Medical School, 185-1, Kohasu, Oko-cho, Nankoku, Kochi 783-8505, Japan. ${ }^{2}$ Advanced Emergency and Critical Care Medical Center, Okayama University Hospital, 2-5-1, Shikata-cho, Kita-ku, Okayama 700-8558, Japan. ${ }^{3}$ Center for Innovative and Translational Medicine, Kochi University Medical School, 185-1, Kohasu, Oko-cho, Nankoku, Kochi 783-8505, Japan.

Received: 9 December 2017 Accepted: 5 April 2018

Published online: 19 April 2018

\section{References}

1. Lunkenheimer PP, Redmann K, Stroh N, Gleich C, Krebs S, Scheld HH, Dietl KH, Fischer S, Whimster WF (1994) High-frequency oscillation in an adult porcine model. Crit Care Med 22(9 Suppl):S37-S48

2. Bostick AW, Naworol GA, Britton TJ, Ori TR, French SK, Derdak S (2012) Inspiratory limb carbon dioxide entrainment during high-frequency oscillatory ventilation; characterization in a mechanical test lung and swine model. Respir Care 57(11):1865-1872

3. Fort P, Farmer C, Westeman J, Johannigman J, Beninati W, Dolan S, Derdak S (1997) High-frequency oscillatory ventilation for adult respiratory distress syndrome-a pilot study. Crit Care Med 25(6):937-947

4. Derdak S, Mehta S, Stewart T, Rogers M, Buchman TG, Carlin B, Lowson S, and the Multicenter Oscillatory Ventilation for Acute Respiratory Distress Syndrome Trial (MOAT) Study Investigators (2002) High-frequency oscillatory ventilation for acute respiratory distress syndrome in adults. A randomized, controlled trial. Am J Respir Crit Care Med 166(6):801-808

5. Fessler HE, Derdak S, Ferguson ND, Hager DN, Kacmarek RM, Thompson T, Brower RG (2007) A protocol for high-frequency oscillatory ventilation in adults: results from a round-table discussion. Crit Care Med 35(7):1649-1654

6. Solway J, Gaveriely N, Slutsky AS, Rossing TH, Drinker P, Saari AF, Drazen JM (1985) Effect of bias flow rate on gas transport during high-frequency oscillatory ventilation. Respir Physiol 60(2):267-276

7. Turner DA, Adams DF, Gentile MA, Lee W, Quick GA, Smith B, Cheifetz IM (2012) Bias flow does not affect ventilation during high frequency oscillatory ventilation in a pediatric animal model of acute lung injury. Pediatric Crit Care Med 13(2):e108-e112

8. Murray JF, Matthay MA, Luce JM, Flick MR (1988) An expanded definition of the adult respiratory distress syndrome. Am Rev Respir Dis 138(3):720-723

9. Young D, Lamb SE, Shah S, MacKenzie I, Tunnicliffe W, Lall R, Rowan K, Cuthbertson BH, OSCAR Study Group (2013) High-frequency oscillation for acute respiratory distress syndrome. New Engl J Med 368(9): $806-813$

10. Liu S, Yi Y, Wang M, Chen Q, Huang Y, Liu L, Xie J, Zhou D, Qiu H (2013) Higher frequency ventilation attenuates lung injury during high-frequency oscillatory ventilation in sheep models of acute respiratory distress syndrome. Anesthesiology 119(2):398-411

11. Acute Respiratory Distress Syndrome Network, Brower RG, Matthay MA, Morris A, Schoenfeld D, Thompson BT, Wheeler A (2000) Ventilation with lower tidal volumes as compared with traditional tidal volumes for acute lung injury and the acute respiratory distress syndrome. N Engl J Med 342(18):1301-1308

12. Sedeek KA, Takeuchi M, Suchodolski K, Kacmarek RM (2003) Determinants of tidal volume during high-frequency oscillation. Crit Care Med 31(1):227-231

13. Hager DN, Fessler HE, Kaczka DW, Shanholtz CB, Fuld MK, Simon BA, Brower RG (2007) Tidal volume delivery during high-oscillatory ventilation in adults with acute respiratory distress syndrome. Crit Care Med 35(6):1522-1529

14. Iguchi N, Hirao O, Uchiyama A, Mashimo T, Nishimura M, Fujino Y (2010) Evaluation of performance of two highfrequency oscillatory ventilators using a model lung with a position sensor. J Anesth 24(6):888-892 
15. Shiba N, Nagano O, Hirayama T, Ichiba S, Ujike Y (2012) Humidification of base flow gas during adult highfrequency oscillatory ventilation: an experimental study using a lung model. Acta Med Okayama 66(4):335-341

16. Hirayama T, Nagano O, Shiba N, Yumoto T, Sato K, Terado M, Ugawa T, Ichiba S, Ujike Y (2014) Mean lung pressure during adult high-frequency oscillatory ventilation: an experimental study using a lung model. Acta Med Okayama 68(6):323-329

17. Pillow JJ (2005) High-frequency oscillatory ventilation: mechanisms of gas exchange and lung mechanics. Crit Care Med 33(3):135-141

Submit your manuscript to a SpringerOpen ${ }^{\circ}$ journal and benefit from:

- Convenient online submission

- Rigorous peer review

- Open access: articles freely available online

- High visibility within the field

- Retaining the copyright to your article

Submit your next manuscript at $>$ springeropen.com 